\title{
FutureJournal
}

\section{Sucesso de Sistemas de Informações na Administração Pública: Proposta de Um Modelo Exploratório}

\author{
Deyvison de Lima Oliveira \\ Doutor em Administração pela Universidade Federal do Rio Grande do Sul, Brasil \\ deyvilima@gmail.com \\ Elíbia Paola da Silva Ferreira \\ Graduanda em Ciências Contábeis pela Universidade Federal de Rondônia, Brasil \\ 09elibia@gmail.com
}

\author{
Alexandre de Freitas Carneiro \\ Mestre em Administração pela Universidade Federal de Rondônia, Brasil \\ alexandrevha95@gmail.com
}

\section{Robinson Francino da Costa}

Mestre em Administração pela Faculdade de Estudos Administrativos de Minas Gerais (FEAD), Brasil

professorrobinson@gmail.com

\section{Wellington Silva Porto}

Mestre em Engenharia de Produção pela Universidade Federal de Santa Catarina, Brasil wsporto2009@gmail.com

\section{RESUMO}

Os investimentos em Sistemas de Informação (SI) estão aumentando cada vez mais, e consequentemente, persiste a relevância dos estudos sobre sucesso de SI. Delone e Mclean (2003) elaboraram um modelo de sucesso de SI, e esse modelo é referência para as pesquisas da área, porém, na perspectiva do setor público, ainda são raros os estudos. Nesta pesquisa buscou-se propor um modelo exploratório de sucesso de SI na Administração Pública, a partir da identificação de itens em cada construto do modelo original de Delone e McLean (2003), por meio de estudos de casos múltiplos em três prefeituras e uma câmara municipal do Cone Sul do estado de Rondônia. Com base na pesquisa empírica, constatou-se que os fatores de sucesso de SI na Administração Pública Municipal se aproximam daqueles apontados na literatura revisada, porém, com algumas particularidades do setor público. Um modelo de fatores e itens de sucesso de SI, do confronto entre literatura e os dados empíricos, é apresentado ao final. 


\section{FutureJournal}

PALAVRAS-ChaVe: Governo Eletrônico. E-Serviços. E-Governo.

Bibliometria.

\section{Information Systems Success in Public Administration: Proposal of An Exploratory Model}

\section{ABSTRACT}

Investments in Information Systems (IS) are increasing more and consequently remains the relevance of studies about IS success. Delone and Mclean (2003) developed an IS success model, and this model is a benchmark for research in the area, however, in view of the public sector, are still few studies. In this research we sought to propose an exploratory model of IS success in Public Administration, based in the identification of items in each construct of Delone and McLean's (2003) original model, through multiple case studies in three municipalities and a city Council in the Rondônia's southern. Based on empirical research, it was noticed that the IS success factors in Municipal Public Administration approximate those indicated in the literature reviewed, however, with some particularities of the public sector. We presented a model of success factors and IS items, based in the confrontation between literature and empirical data.

KEY-WORDS: Accounting information systems; System of cost information; Information systems success; Municipal Public Administration. 


\section{INTRODUÇÃO}

Com a Revolução Informacional, a sociedade passou a conviver com uma grande disponibilidade de informações. Ela valoriza ainda mais a informação e a disseminação do conhecimento, uma vez que esse processo se tornou bastante dinâmico em decorrência da inovação que a Tecnologia da Informação (TI) proporcionou (Amorim \& Tomaél, 2011). Os investimentos em TI e serviços relacionados têm sido crescentes (Roses, Hoppen, \& Henrique, 2009), a despeito das crises econômicas.

A Nova Contabilidade Pública, que visa à conversão da linguagem contábil brasileira às normas internacionais de contabilidade, contribui para que o setor público incorpore os princípios gerenciais de eficácia, eficiência e avaliação de resultados. Com isso, as empresas e os órgãos desse setor têm procurado adotar práticas de administração da iniciativa privada, a fim de se obter maior competência gerencial (Ching, Silveira, \& Freire, 2011; Cunha \& Miranda, 2013; Engida \& Bardill, 2013). Diante disso, a implantação de sistemas de informação se faz necessária, já que traz impactos tanto no nível individual quanto organizacional, e resulta em experiências de sucesso ou fracasso que remetem a múltiplas dimensões de análise (Amorim \& Tomaél, 2011; Fernandes, Jóia, \& Andrade, 2012).

A tecnologia da informação e comunicação eletrônica estão cada vez mais incorporadas nas atividades governamentais. Um exemplo é a implementação do SPED (Sistema Público de Escrituração Digital), cuja a finalidade é aproximar o fisco de seus contribuintes, controlando a arrecadação de tributos (Geron, Finatelli, Faria, \& Romeiro, 2011). As correntes de pesquisa sobre sistemas ERP se concentram, principalmente, na adoção do ERP e fatores críticos de sucesso (Matende \& Ogao, 2013).

Tendo em vista o incentivo de Delone e Mclean (2003) para o desenvolvimento de dimensões e medidas de sucesso de SI em observância aos contextos específicos e aos atores envolvidos, os sistemas de informações contábeis e de custos aplicados às organizações públicas são oportunidades de investigações no Brasil, considerando o reduzido número de pesquisas na área e o momento de transição e de implantação dos sistemas de custos pela gestão pública. Portanto, o objetivo desse estudo é propor um modelo 
exploratório de sucesso de SI na administração pública a partir da identificação de itens em cada construto do modelo original de Delone e McLean (2003), e para atingi-lo, foram realizados estudos de caso em três prefeituras municipais e uma câmara municipal do Cone Sul do estado de Rondônia.

Este estudo faz duas contribuições à área de SI na Administração Pública:

i) Proposição de modelo exploratório para avaliação da pós-adoção de SI: os modelos de sucesso de SI da literatura são predominantemente aplicados às organizações de negócios. O modelo específico para a Administração Pública Municipal poderá contribuir com a avaliação de desempenho dos sistemas em uso, incluindo vantagens e desvantagens;

ii) Avaliação de elementos que antecedem a contratação/aquisição de sistemas de informação. A validação do modelo exploratório (resultado desta pesquisa) em estudos seguintes poderá contribuir com a avaliação dos antecedentes a serem analisados na contratação/aquisição de sistemas pela Administração Pública, a exemplo das condições de apoio da alta gestão aos sistemas, da qualidade do serviço e do sistema. Essa análise tende a contribuir com o sucesso da terceirização de SI.

O artigo se estrutura em mais quatro seções, além desta introdução: na seção 2, apresenta-se o referencial teórico que abrange o sucesso de SI, os modelos e construtos, bem como o sucesso de SI na Administração Pública; na seção 3 trata-se do método adotado; na seção 4 são descritos os resultados encontrados em campo, assim como a confrontação da literatura e a realidade das unidades administrativas estudadas; e na seção 5 expõemse as conclusões deste estudo.

\section{SUCESSO DE SI: MODELOS E CONSTRUTOS}

O principal modelo de sucesso de SI na literatura é apresentado por Delone e Mclean (2003). Esse modelo define seis construtos: qualidade da informação, qualidade do sistema, qualidade do serviço, uso, satisfação do usuário e benefícios líquidos do uso (Delone \& Mclean, 2003). 
O construto uso do sistema tem sido retirado dos modelos de pesquisa que testam o sucesso de SI (Gorla, Somers, \& Wong, 2010). Um dos motivos é a amplitude de significados de uso no modelo de Delone e McLean (2003). Outro motivo se refere à pouca utilidade do conceito de uso em sistemas mandatórios, como no caso da administração pública (Gable, Sedera, \& Chan, 2008; Petter, Delone, \& Mclean, 2008), assim como a falta de confiança na informação eletrônica (Amorim \& Tomaél, 2011). Além disso, resultados de pesquisa com sistema de Educação à Distância evidenciam ausência de relação entre os construtos de qualidade (informação, sistema, serviço) e o uso do SI (Sanchez, Cruz, \& Agapito, 2012).

Da mesma forma, o construto satisfação do usuário é retirado de modelos de sucesso de SI, tendo em vista que seus itens podem ser contemplados em construtos como qualidade da informação e do sistema, como destaca Gorla, Somers e Wong (2010). Além dos construtos relacionados ao sistema (qualidade da informação, do sistema e do serviço) e aos benefícios líquidos (impactos organizacionais), a literatura tem indicado antecedentes do sucesso de SI. O principal deles é o suporte da alta gestão (Hartono, Li, Na, \& Simpson, 2010; Zaied, 2012), utilizado nesta pesquisa.

\subsection{SUCESSO DE SI NA ADMINISTRAÇÃO PÚBLICA}

As organizações governamentais estão buscando cada vez mais por profissionalização, eficiência e efetividade. A Nova Gestão Pública e governança está visando à qualidade das informações, através da implantação de instrumentos de mensuração que permitam um monitoramento sistemático do desempenho econômico e financeiro (Martinez \& Alves Filho, 2012). As principais características da Nova Gestão Pública incluem: prestação de serviços de alta qualidade; melhoria no desempenho organizacional e individual; autonomia gerencial, reduzindo o controle centralizado; reconhecimento da importância de fornecer aos gestores e servidores públicos recursos tecnológicos para alcançar metas de desempenho; e receptividade à concorrência ao incorporar princípios do setor privado e organizações não-governamentais (Engida \& Bardill, 2013). 
Os sistemas de informação (SI) são sistemas sociais que lidam com a interação de pessoas e tecnologia. Um sistema de informação, incluindo um sistema (ERP) Enterprise Resource Planning, possui interface do usuário e é projetado para fornecer informações úteis para apoiar a estratégia, operações, análise de gestão e tomada de decisão em diversos cargos de uma organização (Matende \& Ogao, 2013).

As abordagens que enfocam a organização e sua estratégia sustentam que a aplicação da TI apoia a mudança em processos e a transformação da organização, desde que orientada aos objetivos e metas institucionais. E essas abordagens também são aplicadas à área pública: a integração entre sistemas e infraestrutura de TI e o processo de gestão é considerada essencial para a efetividade de resultados e deve refletir a visão estratégica. Assim, é relevante a presença de dirigente político comprometido com o projeto do sistema e apto a manter apoio e a persuasão no ambiente fragmentado da administração pública (Fernandes et al., 2012).

A Figura 1 apresenta o modelo conceitual de pesquisa. Nela os modelos propostos por Delone e Mclean (2003) e Gable et al. (2008) foram utilizados e adaptados para caracterizar o setor público. Por exemplo, os construtos "benefícios no nível de instituição pública" e "benefícios no nível de processos" representam o construto "benefícios líquidos de uso", de Delone e Mclean (2003).

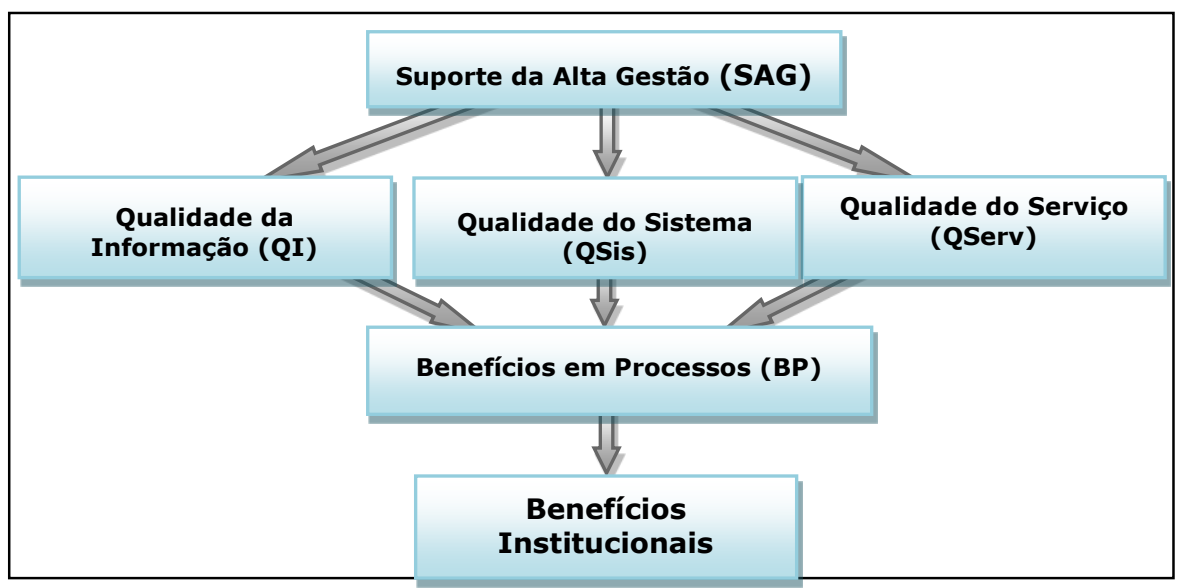

Figura 1: Modelo conceitual de pesquisa

Fonte: Elaborada pelos autores.

\subsection{MODELOS E CONSTRUTOS DE SUCESSO DE SI}


Independentemente do contexto econômico, as organizações necessitam avaliar se a implementação de sistemas de informação foi bemsucedida ou não. Petter, Delone e Mclean (2012) destacam que a missão dos SIs é oferecer um design eficiente e que possibilite a gestão tomar decisões. Adicionalmente, o seu uso efetivo deve impactar não somente seus usuários, como também a sociedade. As organizações avaliam seu sistema de informação por diversas razões, e os impactos positivos são perseguidos. Pesquisas recentes frequentemente buscam uma medida de benefícios líquidos ou impactos do SI. Até o momento, porém, espera-se que o sistema de informação obtenha um fluxo contínuo de benefícios no futuro, já que é um investimento a longo prazo (Gable et al., 2008).

Em 1992, Delone e McLean formularam um modelo teórico a fim de integrar o trabalho de investigação sobre o sucesso de SI que tinha sido feito até aquele momento, bem como fornecer direções para pesquisas futuras. Fora apresentado um modelo de sucesso de SI que tentou captar a natureza multidimensional e interdependente do conceito, e este abordou, inicialmente, seis constructos: qualidade da informação, qualidade do sistema, qualidade do serviço, uso, satisfação do usuário, impactos individuais e impactos organizacionais.

Após dez anos, Delone e McLean (2003) observaram um enorme progresso referente aos impactos do SI na empresa e na sociedade, bem como o progresso na investigação sobre sucesso de SI, e adaptaram o modelo D \& M (2003) a fim de servir como base para pesquisas empíricas sobre SI. Foi adicionado o constructo "qualidade do serviço", e os constructos "impactos individuais" e "impactos organizacionais" uniram-se no constructo "benefícios líquidos", preservando a natureza parcimoniosa do modelo.

A mensuração do sucesso de SI tornou-se cada vez mais complexa, porém sua essência, ainda é simples. A complexidade surge devido ao crescente uso e o aumento do número de usuários de sistemas de informação. Todavia, a mensuração do sucesso dos sistemas de informação em sua essência ainda é simples porque existem elementos-chave consistentes, como a qualidade da informação, sistema de qualidade, uso e resultados. Relevância, oportunidade e precisão das informações ainda são a chave para o sucesso de SI (Petter, Delone, \& Mclean, 2012). 
Gable e Sedera e Chan (2008) destacam que cerca de 60\% dos estudos que empregam os construtos de Delone e Mclean utilizam um único construto. Em consequência, esses autores defendem que parte destes estudos é inadequada e não emprega um subconjunto dos construtos como uma medida global de sucesso. Nesse sentido, os autores utilizaram em seu estudo o "Impacto do SI", que é uma medida de impactos em um ponto no tempo. Também incluíram em seu estudo a medida SI-Organizacional, que reflete $\mathrm{o}$ artefato de TI e os impactos em diferentes pontos no tempo, anteriores e posteriores à satisfação e utilização. Vide na Tabela 1 os aspectos identificados na literatura que caracterizam cada construto - seção 2.2.5.

\subsubsection{Suporte da Alta Gestão}

O suporte da alta gestão (SAG) é uma variável importante para o sucesso do projeto (Hartono et al., 2010; Young \& Poon, 2012). Young e Poon (2012) apresentaram um estudo que relacionou as diferenças entre sucesso de projetos e sucesso de projetos de gerenciamento, e nesse estudo, o SAG mostrou ser o fator mais importante para o sucesso de projeto. Segundo os autores, as abordagens convencionais, que enfatizam as metodologias de projeto, envolvimento do usuário, o planejamento de alto nível e bom projeto pessoal estão em destaque. Um projeto de governança utilizando o SAG pode resolver os problemas persistentes do fracasso do projeto de TI. No setor público, liderança e apoio da alta gestão favorecem o compartilhamento de informação entre órgãos, melhorando sua qualidade, apesar das dificuldades impostas pela pressão do tempo e da carga de trabalho (D. D. L. Oliveira, Girardi, \& Gouveia Neto, 2011).

Em seu estudo, Young e Poon (2012) avaliaram cinco fatores críticos de sucesso: apoio da alta gestão (SAG), metodologia de projeto, o envolvimento do usuário, o planejamento de alto nível e adequação de pessoal. A avaliação da adequação do SAG foi baseada em fatores como a força do compromisso, a sustentabilidade do dirigente, o máximo do compromisso em relação a projetos e velocidade de resposta às questões. Os resultados do estudo, em 15 casos, mostraram que o apoio da diretoria é significativamente mais necessário do que todos os outros fatores críticos de sucesso. 


\subsubsection{Qualidade do Sistema}

Segundo Petter, Delone e Mclean (2008) algumas das características do constructo qualidade do sistema são: a facilidade de uso, a flexibilidade do sistema, a confiabilidade do sistema, e facilidade de aprendizagem, bem como os recursos do sistema de informação, sofisticação, flexibilidade e tempo de resposta.

Em sua pesquisa, Zheng, Zhao e Stylianou (2012) observaram que questões de qualidade do sistema, em termos de como o sistema pode ser eficazmente planejado e gerenciado, melhoraram a experiência do usuário com a comunidade virtual. No tocante às dimensões de qualidade do sistema, os autores afirmam que a navegação é classificada como a dimensão mais importante, pois alivia a sobrecarga de informações. Outra dimensão de qualidade do sistema importante é a segurança, pois o sistema deve implementar mecanismos de controle para proteger informações pessoais.

\subsubsection{Qualidade da Informação}

Petter, Delone e Mclean (2008), Oliveira, Lipke e Silva (2013) e Arazy e Kopak (2011) descreveram as características da qualidade de informação como aquelas desejáveis em relatórios de gestão e nas páginas da web, sendo essas características: relevância, compreensibilidade, precisão, concisão, integralidade, compreensibilidade, pontualidade e usabilidade.

O pronunciamento técnico CPC 00 (CPC, 2011) afirma que as características qualitativas fundamentais das informações nas demonstrações contábeis são a relevância e a representação fidedigna. A relevância diz respeito à influência da informação contábil na tomada de decisões. A representação fidedigna é baseada em três características: a informação completa, neutra e livre de erro. Já as características de melhoria nas informações são: comparabilidade, verificabilidade, tempestividade e compreensibilidade.

Lee et al. (2002) desenvolveram uma metodologia chamada metodologia AIMQ, que fornece uma base rigorosa e pragmática para avaliações de qualidade de informação e benchmarks. A metodologia AIMQ 
tem quatro dimensões de Qualidade de Informação, a saber: QI intrínseca; QI contextual, QI representacional e QI acessibilidade. QI intrínseca implica que a informação tem qualidade. QI Contextual destaca a exigência de que a QI deve ser considerada dentro do âmbito da tarefa em questão, que deve ser relevante, oportuna, completa e adequada em termos de quantidade, de forma a agregar valor. QI representacional e QI acessibilidade enfatizam a importância dos sistemas de computadores que armazenam e fornecem acesso à informação, isto é, o sistema deve apresentar informação de tal forma que seja interpretável, fácil de entender, fácil de manipular, e é representado concisa e coerentemente; outra característica é que o sistema deve ser acessível, mas seguro.

\subsubsection{Qualidade do Serviço}

A informação e a qualidade do sistema afetam diretamente os benefícios individuais, e isso determina a continuidade do fornecimento e utilização da informação pelo usuário (Zheng, Zhao, \& Stylianou, 2012).

Segundo Delone e Mclean (2008), qualidade do serviço pode ser conceituada como a qualidade do apoio que os usuários do sistema recebem do departamento de SI e suporte de TI.

As características da qualidade do serviço são: a capacidade de resposta, precisão, confiabilidade, competência técnica e empatia do staff pessoal. No setor público, os serviços prestados via internet, como no caso dos setores de arrecadação tributária, vêm atenuando o número de contribuintes e contabilistas que se deslocam aos postos de atendimento para a resolução de problemas simples (A. M. N. Nascimento, Luft, Araujo, \& Dacorso, 2011). Ding, Hu e Sheng (2011) defendem que a qualidade do serviço é uma medida que avalia quão bem o nível de serviço prestado atende às expectativas dos clientes.

\subsubsection{Benefícios Organizacionais}


Conforme Delone e Mclean (2008) os benefícios líquidos são considerados na medida em que os Sistemas de Informação estão contribuindo para o sucesso de indivíduos, grupos, organizações, indústrias e nações. As características dos benefícios líquidos são: melhor tomada de decisões, melhoria da produtividade, aumento de vendas, redução de custos, maiores lucros, eficiência do mercado, bem-estar do consumidor, criação de empregos e desenvolvimento econômico.

A literatura tem abordado a necessidade de investigações quanto ao impacto da TI nos diversos processos e capacidades organizacionais. Existem várias medidas para avaliar o impacto de TI nas organizações, podendo ser divididas em dois grupos: desempenho no nível de firma e desempenho no nível inferior ao da firma (Tallon, 2010). O primeiro grupo se refere às medidas de variação de rentabilidade da firma, como retorno sobre os investimentos, retorno sobre o patrimônio dos acionistas, margem de lucro, lucro por ação, produtividade, redução de custos, aumento de receita. O segundo grupo agrega medidas relacionadas com o desempenho de processos, inovação, desempenho de setores, entre outros (D. D. L. Oliveira \& Oliveira, 2013). Logo, nesse estudo, os benefícios organizacionais estão divididos em benefícios em nível de processos e em nível de instituição pública.

\subsubsection{Benefícios no Nível de Processos}

Com relação ao nível de desempenho, pesquisas apontam o nível de processos como o que capta, primeiramente, o impacto da TI, embora esse tenha afinidade com o desempenho no nível da firma (D. D. L. Oliveira \& Oliveira, 2013). As firmas concentram-se na excelência operacional em três aspectos, sendo eles: a procura por custos baixos, confiabilidade, precisão e disponibilidade; a intimidade com o cliente, com foco na qualidade do serviço; ou a liderança do produto, o que significa a inovação de produtos e serviços de ponta (Tallon, 2010).

Os sistemas de informações contábeis podem acrescentar valor à empresa, quando disponibilizam informações exatas e disponíveis. Com isso, aumentam a eficiência e a eficácia da empresa, reduzem os custos dos 
produtos e serviços, melhoram a qualidade da tomada de decisão e contribuem na disseminação do conhecimento (Souza \& Passolongo, 2005). Um exemplo é o uso do internet banking, que nos últimos anos tem promovido a facilidade e rapidez nas transações bancárias (D. L. Oliveira, Lipke, \& Silva, 2013). Esses efeitos poderiam ser estendidos às organizações públicas, com base em resultados de pesquisa.

\subsubsection{Benefícios no Nível de Instituição Pública}

No tocante aos benefícios no nível da organização, estudos afirmam que o desempenho no nível da firma abrange dois itens para mensuração do construto: o aumento no lucro e na participação no mercado (D. D. L. Oliveira \& Oliveira, 2013). Pesquisas na área de TI, na perspectiva de negócios, estão sendo disseminadas em todos os setores. Os aspectos de custos e investimentos em TI impactam o desempenho empresarial. O uso da TI, seja apenas como suporte ou intensamente no processo produtivo, reflete no resultado da empresa (Silva \& Moraes, 2012).

De acordo com Oliveira e Maçada (2013), estudos sobre impactos no desempenho de firma adotam medidas como: retorno sobre os investimentos, retorno sobre o patrimônio dos acionistas, margem de lucro, lucro por ação, participação no mercado, redução nos custos com pessoal e redução nas despesas de vendas, gerais e administrativas. Os sistemas ERP (Enterprise Resource Planning) podem oferecer benefícios intangíveis para as empresas, incluindo melhor informação, processos de negócios internos mais eficientes e melhor coordenação entre as diferentes unidades de uma organização (Hsu, 2013).

Os SIs podem ser avaliados pela relação custo/benefício. Deve-se comparar se as alternativas que os SIs oferecem satisfazem as necessidades informacionais dos administradores (Souza \& Passolongo, 2005).

No setor público, a gestão de sistemas de informação é mais complexa, devido às estratégias terem como finalidade a prestação de contas para o público em geral, mediante justificativa de decisões e ações, assim como a transparência, que demanda um fluxo confiável e tempestivo de informações a todos os interessados (A. M. Nascimento \& Luft, 2012). O 
sistema de informação de custos deveria garantir o atributo da comparabilidade, detalhamento das informações e suprir as necessidades informacionais das diversas unidades organizacionais e seus usuários. A informação de custos proporciona conteúdo fundamental para a tomada de decisões mais eficientes, facilitando a sustentabilidade e o desenvolvimento econômico (Machado \& Holanda, 2010).

Os aspectos que caracterizam cada construto do Modelo conceitual de pesquisa (Figura 1) constam na Tabela 1.

Na seção 3, apresenta-se o método, cujo objetivo é propor um modelo exploratório de sucesso de SI na Administração Pública a partir da identificação de itens em cada construto revisado, a partir do modelo original de Delone e McLean (2003).

\section{Tabela 1: Aspectos encontrados na literatura e referências por construto}

\begin{tabular}{|c|c|c|}
\hline Construto & Aspectos & Adaptado de: \\
\hline \multirow{4}{*}{$\begin{array}{l}\text { Suporte da alta } \\
\text { gestão }\end{array}$} & $\begin{array}{l}\text { Intensidade do suporte de alta gestão, relevância do } \\
\text { suporte. }\end{array}$ & (Hartono et al., 2010) \\
\hline & Apoio do gestor municipal para o projeto de TI. & (Young \& Poon, 2012) \\
\hline & $\begin{array}{l}\text { Compartilhamento entre os departamentos e órgãos } \\
\text { municipais. }\end{array}$ & (D. D. L. Oliveira et al., 2011) \\
\hline & Altos investimentos em TI. & (Fernandes et al., 2012) \\
\hline \multirow{6}{*}{$\begin{array}{l}\text { Qualidade do } \\
\text { sistema }\end{array}$} & Facilidade do uso de SI. & (Petter et al., 2008) \\
\hline & $\begin{array}{l}\text { Aumento de receitas, agilidade nos procedimentos } \\
\text { organizacionais. }\end{array}$ & (Zheng et al., 2012) \\
\hline & Informações úteis para a tomada de decisão. & (Matende \& Ogao, 2013) \\
\hline & Redução de custos operacionais. & (Seethamraju \& Sundar, 2013) \\
\hline & & Continua \\
\hline & & Continuação \\
\hline \multirow{4}{*}{$\begin{array}{l}\text { Qualidade da } \\
\text { informação }\end{array}$} & SI atualizado, com informações confiáveis. & (D. L. Oliveira et al., 2013) \\
\hline & $\begin{array}{l}\text { SI contábil com informações completas, representando } \\
\text { a real situação da organização. }\end{array}$ & $(\mathrm{Cpc}, 2011)$ \\
\hline & SI com informações precisas. & (Petter et al., 2012) \\
\hline & Proteção do acesso ao SI, por meio de senhas. & (Lee, Strong, Kahn, \& Wang, 2002) \\
\hline \multirow{4}{*}{$\begin{array}{l}\text { Qualidade do } \\
\text { serviço }\end{array}$} & Confiabilidade do serviço. & (Petter et al., 2008) \\
\hline & Satisfação dos contribuintes. & (Ding, Hu, \& Sheng, 2011) \\
\hline & Serviço por internet rápido. & (A. M. N. Nascimento et al., 2011) \\
\hline & Gerenciamento eficiente do fornecimento de serviços. & $\begin{array}{l}\text { (Biancolino, Maccari, Kniess, \& } \\
\text { Costa, 2011) }\end{array}$ \\
\hline \multirow{2}{*}{$\begin{array}{l}\text { Benefícios no } \\
\text { nível de } \\
\text { processos }\end{array}$} & Confiabilidade e eficácia nos processos. & $\begin{array}{l}\text { (D. D. L. Oliveira et al., 2011); } \\
\text { (Tallon, 2010) }\end{array}$ \\
\hline & Redução de custos operacionais. & (Tallon, 2010) \\
\hline
\end{tabular}




\begin{tabular}{lll} 
& \multicolumn{1}{l}{ As atividades operacionais dependem do SI. } & (A. M. Nascimento \& Luft, 2012) \\
\cline { 2 - 3 } & Inovação dos processos organizacionais. & (Perez et al., 2012) \\
\cline { 2 - 3 } & Aperfeiçoamento dos produtos e serviços. & (Tallon \& Kraemer, 2007) \\
\cline { 2 - 3 } $\begin{array}{l}\text { Satisfação dos contribuintes e melhora na tomada de } \\
\text { decisão. }\end{array}$ & (Tallon \& Kraemer, 2007) \\
\hline $\begin{array}{c}\text { Benefícios no } \\
\text { nível de } \\
\text { instituição } \\
\text { pública }\end{array}$ & Superávit das instituições governamentais. & $\begin{array}{l}\text { (Ching et al., 2011); (D. D. L. } \\
\text { Oliveira \& Maçada, 2013) }\end{array}$ \\
\cline { 2 - 3 } & Alto impacto de TI no desempenho organizacional. & (Ching et al., 2011) \\
\cline { 2 - 3 } & Tomadro de decisões mais eficientes. & (Machado \& Holanda, 2010). \\
\cline { 2 - 3 } & Avaliação do custo/benefício gerado pela TI. & (Souza \& Passolongo, 2005) \\
\hline
\end{tabular}

Fonte: Elaborada pelos autores

\section{MÉTODO}

O procedimento metodológico adotado é o estudo de casos, que investiga um fenômeno contemporâneo em profundidade e o seu contexto (Yin, 2010). O estudo de caso é caracterizado pelo estudo profundo e exaustivo de um ou mais objetos, permitindo um amplo e detalhado conhecimento (Gil, 2010). Esta pesquisa é exploratória, pois tem como finalidade desenvolver, esclarecer e modificar conceitos e ideias, formulando problemas mais precisos ou hipóteses que podem ser pesquisadas em estudos posteriores. De acordo com Gil (2010), esse tipo de pesquisa é realizado quando o tema é pouco estudado.

Utilizou-se a entrevista semiestruturada para identificar a relação entre os construtos do modelo com a realidade das instituições públicas municipais, bem como a observação direta e a análise dos demonstrativos contábeis encontrados nos websites dos órgãos públicos estudados. A unidade de análise é formada por três prefeituras municipais e uma câmara municipal do Cone Sul do estado de Rondônia. Foram entrevistados seis servidores dos setores de contabilidade, controladoria e auditoria, e gestores públicos municipais.

\subsection{COLETA DE DADOS}


Para a coleta dos dados, optou-se pela entrevista semiestruturada, com vários tipos de questões, incluindo questões abertas, bem como a observação direta e a análise documental. A entrevista é definida por Gil (2010) como "uma forma de diálogo assimétrico, em que uma das partes busca coletar dados e a outra se apresenta como fonte de informação".

A segunda técnica de coleta de dados utilizada é a observação direta. Segundo Yin (2010), as observações diretas podem ser feitas durante a visita de campo e em ocasiões em que outras fontes de evidência estão sendo aplicadas, como por exemplo, no momento das entrevistas.

Outra técnica utilizada foi a análise documental das demonstrações encontradas, a saber: Relatório Resumido de Execução Orçamentária (RREO), Relatório de Gestão Fiscal (RGF) e Portal da Transparência nos websites das unidades de análise pesquisadas. De acordo com Yin (2010), a análise documental é utilizada para confirmar e aumentar a evidência de outras fontes. O autor também afirma que a revisão de documentos relevantes desempenha um papel fundamental em qualquer plano de coleta de dados.

\subsection{ANÁLISE DE DADOS}

Realizou-se a análise de conteúdo das entrevistas, da observação direta e dos demonstrativos encontrados nos websites dos órgãos públicos pesquisados, a fim de elaborar um modelo exploratório de sucesso de SIs contábeis e de custos na administração pública municipal.

Para elencar esses fatores, usou-se a análise de conteúdo, que é conceituada por Bardin (2011, p. 44) como:

Um conjunto de técnica de análises das comunicações visando obter, por procedimentos sistemáticos e objectivos de descrição do conteúdo das mensagens indicadores (quantitativos ou não) que permitam a inferência de conhecimentos relativos às condições de produção/recepção (variáveis inferidas) destas mensagens.

Gil (2010) conceitua a análise de dados como uma técnica de investigação que tem por finalidade a interpretação dos conteúdos coletados, através de uma descrição objetiva, sistemática e quantitativa. Segundo o 
autor, a análise tem como objetivo organizar os dados de forma que possibilitem o fornecimento de respostas ao problema proposto.

As categorias usadas para análise de conteúdo compreendem os itens da Tabela 1. Os dados obtidos nas entrevistas, observação direta e demonstrativos contábeis foram confrontados com os itens da Tabela 1, que correspondem aos aspectos de sucesso de SI apresentados na literatura. Essa análise tem como objetivo verificar se os fatores de sucesso de SI encontrados na literatura estão de acordo com a realidade dos entes públicas municipais, e se existem outros aspectos que deixaram de ser mencionados pela literatura.

\section{RESULTADOS E DISCUSSÕES}

Foram feitas entrevistas com os servidores públicos da controladoria e contabilidade, de três prefeituras municipais e uma câmara municipal do Cone Sul do estado de Rondônia, totalizando 6 entrevistas, sendo três servidores da Prefeitura A, um servidor da Prefeitura B, um servidor da Prefeitura C e um servidor da Câmara Municipal A. As entrevistas duraram aproximadamente 15 a 25 minutos cada uma. Utilizou-se a Tabela 1 como base para a entrevista semiestruturada [com base em protocolo de estudo de caso], a fim de se confirmar se os fatores encontrados na literatura correspondem à realidade dos entes municipais, e também para acrescentar algum aspecto não mencionado na literatura. Foram analisados os RGF e os RREO das prefeituras e câmara estudadas. Quanto à observação direta, foram colhidas informações durante as visitas nas unidades administrativas pesquisadas.

\subsection{RESULTADOS}

Nesta seção, serão expostos os resultados encontrados por meio das entrevistas e visitas feitas às Prefeituras Municipais e Câmara Municipal. A tabela 2 descreve as características de cada entrevistado e o respectivo órgão público. Em duas prefeituras e na câmara municipal, foi entrevistado apenas 
um servidor, devido à indisponibilidade de outros servidores em participar nas entrevistas.

Nas seções seguintes, os resultados são apresentados por construto do modelo conceitual, de acordo com os achados da fase empírica da pesquisa. No Apêndice A consta o modelo exploratório de Sucesso de SI resultante da pesquisa.

\section{Tabela 2: Caracterização das unidades administrativas estudadas}

\begin{tabular}{|c|c|c|c|c|}
\hline $\begin{array}{l}\text { Órgão } \\
\text { Público }\end{array}$ & $\begin{array}{c}\text { Orçamento } \\
\text { anual - } \\
\text { Realizado } \\
(2013-\mathbf{R} \$)\end{array}$ & $\begin{array}{l}\text { Setor - Unidade } \\
\text { Administrativa }\end{array}$ & $\begin{array}{l}\text { Tempo de } \\
\text { serviço } \\
\text { público }\end{array}$ & $\begin{array}{c}\text { Sistemas de } \\
\text { Informações } \\
\text { (contábeis/custo) }\end{array}$ \\
\hline \multirow{3}{*}{ Prefeitura A } & \multirow{3}{*}{$166.438 .500,27$} & Controladoria & 7 anos & Contábeis \\
\hline & & $\begin{array}{c}\text { Contabilidade - SEMFAZ } \\
\text { (Secretaria Municipal de } \\
\text { Fazenda) }\end{array}$ & 6 anos & Contábeis \\
\hline & & $\begin{array}{c}\text { Contabilidade - SEMUSA } \\
\text { (Secretaria Municipal de } \\
\text { Saúde) }\end{array}$ & 18 anos & Contábeis \\
\hline Prefeitura B & $32.548 .532,30$ & Controle Interno & 18 anos & Contábeis \\
\hline Prefeitura C & $28.390 .999,33$ & Contabilidade & 9 anos & Contábeis \\
\hline Câmara A & $24.628 .244,90$ & Diretoria & 1,5 ano & Contábeis \\
\hline
\end{tabular}

Fonte: Elaborada pelos autores.

Uma representação gráfica do modelo exploratório de sucesso de SI obtido na pesquisa empírica - com o número de indicadores (itens) em cada construto - é apresentada na Figura 2 e discutida nas seções seguintes. 


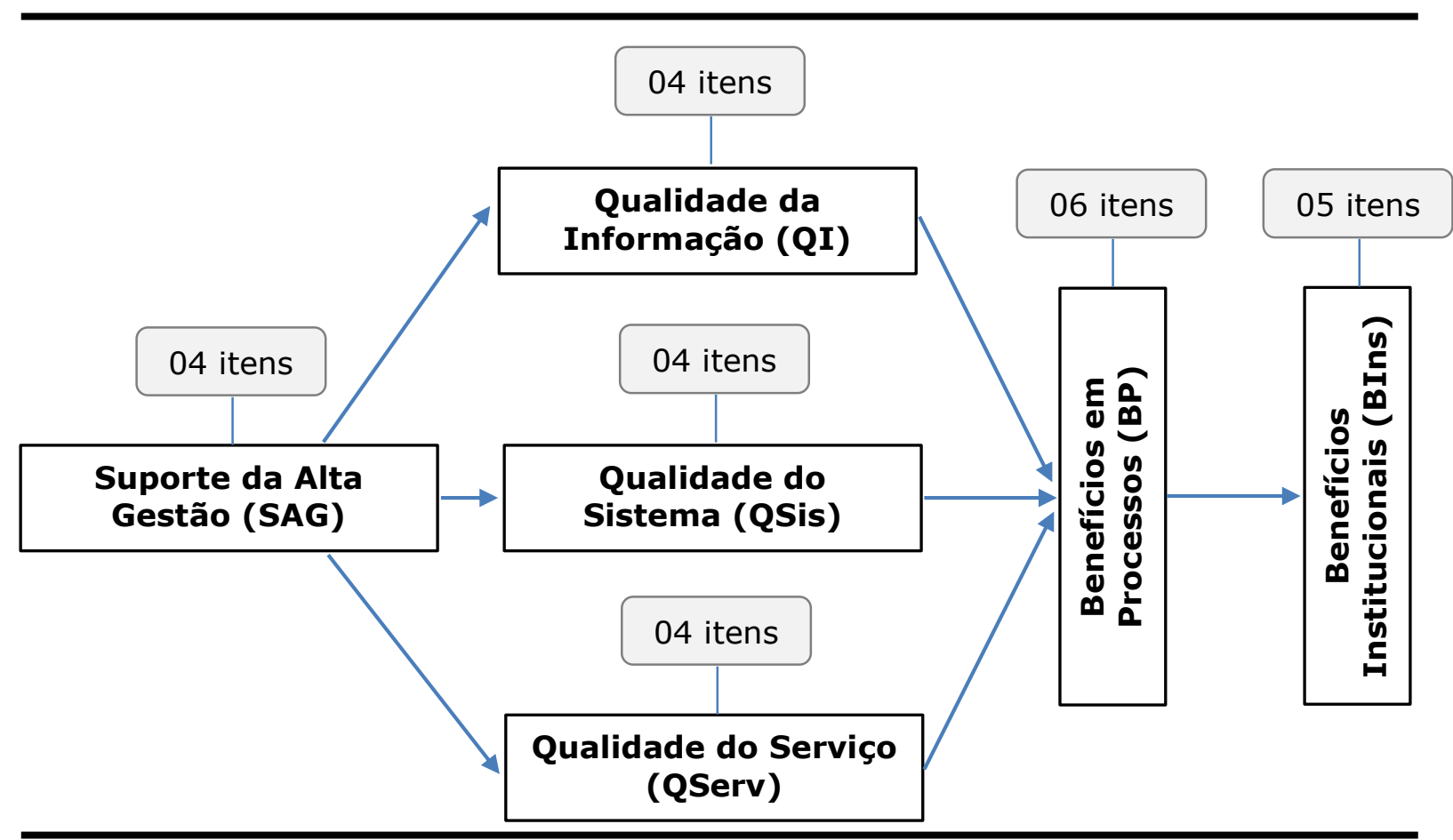

Figura 2: Representação gráfica do modelo exploratório de sucesso de SI: pesquisa empírica.

Fonte: Elaborado pelos autores.

\subsubsection{Suporte da Alta Gestão}

Todos os servidores afirmaram que o gestor se preocupa em cumprir as normas, logo, essa preocupação se estende indiretamente à implantação de sistemas de informações. Percebeu-se que, nas prefeituras A, B e C, e na Câmara A, o suporte da alta gestão é um fator importante, porém, a preocupação dos gestores municipais são o cumprimento das normas. Portanto, a implementação dos sistemas ocorre somente para esse fim. Conforme o servidor da Prefeitura B, "embora seja necessário, a Administração é pouco consciente do objetivo do SI".

Quanto aos investimentos em SI, na Prefeitura A os entrevistados afirmaram que sempre há investimentos, e que os custos para implementação de SI são altos. O servidor da Prefeitura B afirmou que existem investimentos, mas ainda não é o suficiente. Já a servidora da Prefeitura $C$ alegou que existem investimentos na área de SI, porém eles não são a prioridade da Administração. E o servidor da Câmara A afirmou que há bastante investimento em SI nessa unidade administrativa. As informações entre as unidades administrativas são compartilhadas, tanto nas Prefeituras 
A, B e C, como na Câmara A, conforme observado em campo. De acordo com a servidora da Prefeitura C, "antes levávamos dois dias para importar uma folha de pagamento para a contabilidade, hoje levamos apenas meia hora, então, o compartilhamento de informações entre as unidades administrativas é importante".

\subsubsection{Qualidade do Sistema}

No que se refere à facilidade de uso do SI contábil e de custo, na Prefeitura A o sistema contábil é de fácil uso, e o de custos ainda está em fase de implantação. A servidora da Prefeitura A ressalta que a experiência do usuário torna o uso do sistema menos dificultoso, e que os usuários precisam aprimorar o conhecimento constantemente. Na Prefeitura C e na Câmara A, o sistema de custos ainda está em fase de implantação.

Quanto à agilidade que o SI proporciona para as atividades organizacionais, todos os servidores concordaram que o sistema contábil é ágil, e colabora para que a informação requerida pelo gestor seja apresentada tempestivamente.

Nas Prefeituras e Câmara Municipal pesquisadas, todos apoiam a ideia de que o sistema é relevante para a tomada de decisão, pois ele permite controlar os gastos públicos. A servidora da Prefeitura C certifica que o SI é importante para a tomada de decisão, porém, as informações devem ser conferidas, para que os erros não comprometam negativamente as decisões. Segundo a servidora da Prefeitura C, o sistema de informação deve estar de acordo com as Normas Brasileiras de Contabilidade Aplicada ao Setor Público (NBCASP), pois se não estiverem, eles precisarão fazer manualmente, e isso compromete a confiabilidade das informações. Por isso, os responsáveis pelo software devem providenciar as mudanças dentro do prazo, para que os servidores públicos não tenham prejuízo.

Sobre a redução de custos devido ao uso do sistema de informação, na Prefeitura C e na Câmara A, houve redução de impressão de papel, custo com manutenção de impressora e o custo referente ao tempo para se realizar determinada atividade. Segundo a servidora da Prefeitura C, os custos operacionais reduziram, pois eles enviam as informações eletronicamente 
para o Tribunal de Contas, porém, eles ainda enviam os relatórios impressos para o Legislativo, e isso representa um custo para a Prefeitura. Na Prefeitura A, são enviadas duas versões de relatório para o Tribunal de Contas, que é a versão impressa e a digitalizada. A servidora da Prefeitura A não soube informar se os custos operacionais diminuíram ou não. A outra servidora da Prefeitura $A$ afirmou que houve uma redução de custos quanto aos gastos com pessoal para auxiliar no setor de contabilidade. Na Prefeitura B, não há informações para se mensurar o custo.

\subsubsection{Qualidade da Informação}

Na Prefeitura A, as informações prestadas são confiáveis, e são conferidas diariamente, assim como nas Prefeituras B e C, e na Câmara A.

Na Prefeitura A as informações prestadas são relevantes, fidedignas, além de serem comparáveis, verificáveis, tempestivas e compreensíveis. Um dos entrevistados dessa prefeitura informou que o SI é alimentado diariamente, sendo as informações conferidas, e que a Prefeitura Municipal tem a obrigação de atualizar o Portal da Transparência, embora esse Portal enfrente alguns problemas, quanto a capacidade do site. Na Prefeitura B e na Prefeitura C, as informações são confiáveis, pois o Portal da Transparência deve ser alimentado diariamente, mas as prefeituras estão com problemas quanto a contratação de um prestador de serviço para organizar as informações no Portal.

Os entrevistados também confirmaram que as informações prestadas refletem a realidade da Prefeitura, portanto, as informações são precisas e oportunas. Porém, o site do Portal da Transparência das prefeituras e câmara pesquisados estão com algumas informações desatualizadas. Em consequência disso, se o contribuinte quiser conhecer sobre as demonstrações das Prefeituras e Câmaras, eles devem ir pessoalmente ao órgão e solicitar.

Nas prefeituras e câmara municipal estudados, cada funcionário, dependendo da sua função, tem acesso a determinado módulo do SI, e seu acesso fica restrito a apenas determinada função. A servidora da Prefeitura C 
assegurou que os funcionários públicos têm o acesso restrito à determinada responsabilidade, mas que, depois, essas informações são consolidadas.

\subsubsection{Qualidade do Serviço}

Em todas as prefeituras e câmara municipal estudadas, quem presta o serviço de TI é uma empresa privada. Quanto à confiabilidade do serviço, os servidores da Prefeitura A, Prefeitura C e Câmara A confirmaram que o serviço prestado pelo pessoal de TI é confiável, já o servidor da Prefeitura $B$ não opinou, pois segundo ele, na prefeitura mencionada não há setor de TI, o que existe é um funcionário que apenas auxilia na resolução de alguns problemas. No que se refere à satisfação dos funcionários, um dos servidores da Prefeitura A disse que "como o prestador de serviço é de outro estado, à medida que recebemos uma notificação do Tribunal de Contas, nós enviamos uma solicitação para eles, e eles fazem as adequações". O servidor da Prefeitura B não opinou sobre esse aspecto. Na Prefeitura C, o prestador de serviço de TI busca a satisfação dos servidores, porém, deixa a desejar quanto ao tempo de resposta para atendimento a uma solicitação. Por outro lado, na Câmara A o prestador de serviço de TI satisfaz as necessidades dos servidores dessa unidade administrativa.

Na Prefeitura A, os entrevistados acreditam que a internet disponível no estado não é ágil, pois só tem um provedor, o que reduz a capacidade do sinal. Quanto à Prefeitura B, o entrevistado afirmou que "a disponibilização de sinal dificulta para que o cidadão acesse as informações". Na Prefeitura C e na Câmara A, o sinal fraco da internet representa $90 \%$ dos problemas existentes, e que para solucioná-los, o gestor público teria que priorizar os investimentos para aumentar a capacidade da internet.

Quanto ao aspecto do gerenciamento eficaz de serviço, na Prefeitura A uma das servidoras disse que pelo fato de a demanda de serviço ser muito grande, "às vezes os prestadores de serviço não atendem as necessidades a tempo"; outro entrevistado assegura que o serviço vem melhorando, e a outra afirma que o serviço é gerenciado de maneira eficiente. Na Prefeitura B, o servidor não opinou sobre esse aspecto. Quanto a Prefeitura C, a contadora afirma que o serviço é gerenciado de maneira eficiente, porém a 
rotatividade de funcionários das empresas privadas é grande, e isso atrapalha quanto a solução dos problemas rotineiros. O entrevistado da Câmara A garante que o serviço é gerenciado de maneira eficiente, pois atende às necessidades do órgão.

\subsubsection{Benefícios em Nível de Processos}

Em todas as prefeituras e câmara municipal os entrevistados garantem que com a adoção do SI, os processos se tornam confiáveis e eficazes, e o servidor da Prefeitura B acrescentou que os processos são confiáveis, desde que haja um acompanhamento.

Em relação à diminuição de custos operacionais nos últimos três anos, na Prefeitura $A$ os custos diminuíram, um exemplo é a área da saúde, que possui uma grande demanda de serviço, e o SI auxilia na execução das atividades desse setor. Na Prefeitura B houve uma redução no custo quanto à impressão, os relatórios são enviados digitalmente para o Tribunal de Contas; somente para a Câmara os servidores enviam os relatórios impressos. Na Prefeitura C, os custos reduziram quanto ao tempo para se elaborar um relatório, atenuando as despesas com pessoal. Na Câmara A também houve uma redução de custos.

Em todas as prefeituras e na câmara municipal, os entrevistados também concordaram que o sistema é indispensável para a realização dos processos organizacionais, nos últimos três anos. Todos os entrevistados confirmam que nesse período o uso do SI proporcionou inovação nos processos organizacionais, porém, essas inovações devem corresponder ao que as normas estabelecem. Todos concordam também que o serviço de SI é aprimorado. Uma das entrevistadas da Prefeitura A completou que "você tem que estar inovando, senão fica para trás".

Na Prefeitura A todos os entrevistados concordam que a relação com os contribuintes melhorou nos últimos três anos, devido ao fato de o cidadão poder emitir os tributos municipais eletronicamente. Quanto à Prefeitura B, 0 Portal da Transparência é um elo entre o contribuinte e a Prefeitura, e o sistema contribui para a redução da evasão fiscal. Na Prefeitura C, existe um problema quanto ao atendimento ao contribuinte, pois a emissão de taxas, 
certidões e notas fiscais são feitas na Prefeitura, em consequência da indisponibilidade de um sistema eletrônico e da reduzida capacidade de internet na cidade. Na Câmara A, o SI melhorou a relação com os cidadãos, em relação ao acesso às sessões ordinárias, às leis e decretos, por meio da internet.

\subsubsection{Benefícios em Nível de Instituição Pública}

Nos últimos três anos, as receitas aumentaram na Prefeitura $A$, devido ao uso do SI, e comparando-se às outras prefeituras estudadas, a Prefeitura A possui a maior receita realizada. Quanto à Prefeitura $B$, houve uma melhoria pelo fato de ter diminuído as despesas com pessoal. Na Prefeitura $C$ e Câmara $A$, houve resultados positivos nesse período, e a servidora da Prefeitura C completou que comparado às outras prefeituras, houve uma melhoria no quesito de integração das informações contábeis.

Na Prefeitura $A$, nos últimos três anos o SI proporcionou melhora nas despesas públicas, pois o gestor tem controle das informações sobre o dinheiro público aplicado, sendo essas informações atualizadas. Na Prefeitura B, e Câmara A, o gasto público também melhorou devido ao uso do SI para a tomada de decisão. E na Prefeitura C, a servidora afirmou que esse quesito de melhora de gasto público não depende apenas do SI, mas também das políticas públicas e das decisões tomadas pelo gestor público.

Em todas as unidades administrativas estudadas, nos últimos três anos, os investimentos em TI beneficiaram a população. O servidor da Prefeitura B acrescentou que a informação está mais acessível para o cidadão, através do Portal da Transparência, e os SI são responsáveis por gerar informações para esse site. Nas unidades administrativas estudadas, todos os entrevistados apoiam a ideia de que a informação de custos proporciona conteúdo fundamental para a tomada de decisões mais eficientes, porém os custos ainda não são apurados nas unidades administrativas estudadas.

Nas prefeituras e câmara municipal estudadas os sistemas de informações são avaliados pela sua relação custo/benefício, e é por meio da licitação que ocorre esse processo de avaliação. A servidora da Prefeitura C 
completou que por mais que o sistema seja caro, o que importa é o benefício gerado pelo uso desse sistema.

$\mathrm{Na}$ seção seguinte, são apresentadas as discussões sobre os resultados encontrados, a fim de propor um modelo exploratório de sucesso de SI na Administração Pública a partir da identificação de itens em cada construto do modelo original de Delone e McLean (2003).

\subsection{DISCUSSÃO}

Observa-se que os resultados encontrados nas prefeituras municipais e câmara municipal estudados se aproximam do modelo da literatura, acrescentando-se as peculiaridades do setor público. Hartono et al. (2010), Young e Poon (2012) e Fernandes, Jóia e Andrade (2012) afirmam que o suporte da alta gestão para o uso dos sistemas contábeis e de custos deve ser alto, e isso se aplica à realidade das unidades administrativas estudadas, porém o gestor público se preocupa, essencialmente, em cumprir normativas. Nas prefeituras e câmara estudadas, as informações são compartilhadas entre as unidades administrativas, reduzindo o tempo para realizar determinadas atividades, concordando com Hartono et al. (2010) e Oliveira, Girardi e Gouveia Neto (2011).

Os sistemas contábeis dos órgãos públicos estudados apresentam facilidade no uso e de aprendizagem, confiabilidade, flexibilidade, corroborando com as qualidades do sistema que Petter, Delone e Mclean (2008) descrevem em seu estudo. Nas prefeituras e câmara municipal estudadas, há agilidade nos procedimentos organizacionais, devido ao uso do SI, contribuindo para que o gestor tenha controle sobre os gastos, concordando com Zheng, Zhao e Stylianou (2012) no que se refere a agilidade nos processos organizacionais.

Matende e Ogao (2013) garantem que o sistema de informação fornece informações úteis para a tomada de decisão. E isso se confirma nas unidades administrativas estudadas, pois o sistema contábil fornece informações úteis para a tomada de decisão, desde que essas informações sejam conferidas e que estejam de acordo com as NBCASP. Em todas as prefeituras e câmara municipal estudadas, os entrevistados confirmaram que 
as informações contidas no SI contábil são atualizadas e confiáveis, concordando com Oliveira, Lipke e Silva (2013), que descrevem esses aspectos da qualidade de informação.

Conforme o CPC 00 (2011) e Petter, Delone e Mclean (2012), a informação contábil deve ser relevante, fidedigna, além de ser comparável, verificável, tempestiva e compreensível. Em todos os órgãos públicos estudados, o SI deve apresentar essas características, devido à obrigatoriedade de alimentar o Portal da Transparência.

Nas prefeituras e câmara municipal estudados, cada servidor público tem uma senha de acesso, de acordo com cada função e responsabilidade, e depois as informações contidas em cada função são consolidadas, conforme Lee et al. (2002) defendem em seu estudo.

Nos órgãos públicos em tela, de acordo com o que foi observado em campo, o serviço prestado pelo pessoal da TI é confiável, porém necessita de um tempo de resposta ágil, e isso está alinhado ao que foi encontrado no estudo de Petter, Delone e Mclean (2008). Nas unidades administrativas em questão, o serviço de TI prestado atende às necessidades dos funcionários públicos, conforme o que Ding, Hu e Sheng (2011) defendem. Quanto à satisfação dos cidadãos, nenhum dos entrevistados opinaram.

Nascimento et al. (2011) defendem, em seu estudo, que a prestação do serviço via internet está mais rápida e eficaz. Nas prefeituras e câmara analisadas, o serviço via internet possui alguns problemas de capacidade de sinal, por isso, a demanda por melhorias do serviço na região do Cone Sul, considerando que alguns serviços prestados pelas prefeituras e câmara dependem da internet. Portanto, a realidade da região estudada ainda se distancia da afirmação dos autores supracitados.

Nos órgãos públicos estudados, o SI contábil é produto de empresas privadas, e os entrevistados confirmaram que o serviço de SI é gerenciado de maneira eficiente, corroborando com o que Biancolino et al. (2011) afirmam, mas com algumas falha, devido à rotatividade de funcionários das empresas privadas. Comparando-se o desempenho dos últimos três anos, pode-se dizer que os processos organizacionais são confiáveis e eficazes, porém devem ser acompanhados diariamente. Essa afirmação corrobora os 
achados nas pesquisas de Oliveira, Girardi e Gouveia Neto (2011) e Tallon (2010).

Outro benefício no nível de processos, mencionado por Tallon (2010), é a redução de custos, melhorando o desempenho organizacional. Nos últimos três anos, houve uma redução de custo, quanto à impressão de papel, de gastos com pessoal, bem como a redução de tempo para se elaborar os relatórios. Nascimento e Luft (2012) asseguram que os sistemas de informação são parte do processo devido à sua capacidade de transformar dados brutos em um produto. Nas unidades administrativas, essa subcategoria confirma-se, pois os SIs contábeis são indispensáveis para a realização das atividades públicas.

Nas unidades administrativas estudadas, o SI contábil proporcionou inovação nos processos, porém esses processos se prendem às normas do setor público, logo, isso corrobora em parte com Perez et al. (2012), quando os autores afirmam que a inovação contínua em SI/TI converte o uso de tecnologia em processos e aplicações inovadoras.

Nas unidades administrativas estudadas, essas características se confirmam. O uso do SI proporcionou melhoria nas relações com os contribuintes, pois esses podem acompanhar as atividades das unidades pelo Portal da Transparência, porém ainda existe o problema com o servidor de internet, o que dificulta ou atrasa algum procedimento. Outro aspecto observado nas unidades administrativas refere-se ao aprimoramento do produto/serviço. Essas informações estão de acordo com Tallon e Kraemer (2007).

Nos últimos três anos, nas prefeituras e câmara municipal estudadas, houve uma melhora no desempenho das unidades administrativas, devido ao aumento de receitas durante esse período. Isso confirma o que defendem Ching, Silveira e Freire (2011), quando afirmam que um dos benefícios no nível de instituição é a otimização dos resultados dos programas governamentais. Outro aspecto citado pelos autores é a maior qualidade do gasto público, sendo essa informação observada em campo, porém, essa qualidade não depende apenas do SI, depende também de políticas públicas e das decisões do gestor público. 
Em todas as unidades administrativas estudadas, os investimentos em TI melhoraram o serviço público prestado aos contribuintes, sendo o Portal da Transparência um elo entre os órgãos públicos e a população (Silva \& Moraes, 2012). Todos os entrevistados confirmaram o que Machado e Holanda (2010) dizem sobre o fato de a informação de custos proporcionar conteúdo fundamental para a tomada de decisões mais eficientes. Nos órgãos analisados, todos os entrevistados acreditam que as informações geradas pelo SI de custos serão importantes para a tomada de decisão, porém a prioridade é atender a lei. Em nenhuma das unidades administrativas o SI de custo está implantado. O prazo legal para implantar, de forma completa o SI de custos, é até o final de 2014.

Nos últimos três anos, nas prefeituras e câmara municipal estudados, foram feitas avaliações de custo/benefício gerado pelo SI, através da licitação, procedimento no qual são avaliados os preços, e a qualidade do serviço/produto, e essa avaliação está de acordo com o que diz Souza e Passolongo (2005).

\section{CONCLUSÕES E RECOMENDAÇÕES DE PESQUISA}

Nesta pesquisa, buscou-se propor um modelo exploratório de sucesso de SI na Administração Pública, a partir da identificação de itens em cada construto do modelo original de Delone e McLean (2003). Com base na pesquisa empírica, conclui-se que os fatores de sucesso de SI contábeis das três prefeituras e câmara municipal estudados se aproximam daqueles apresentados no referencial teórico, porém, com algumas peculiaridades do setor público. Quanto ao SI de custos, não foi possível avaliar, por esse sistema ainda constar em fase de implantação nas unidades administrativas analisadas.

Enquanto que nas entidades privadas os SIs são importantes para aumentar receita, no setor público eles se tornam benefícios indiretos para a população. A Nova Contabilidade Pública (regulamentada pelo Decreto no 200/2007) incentivou os órgãos públicos a incorporarem conceitos das entidades privadas, e em consequência disso, o Portal da Transparência foi criado a fim de manter a população informada sobre a aplicação dos recursos 
públicos, e percebeu-se no presente estudo que as informações encontradas nesse portal estão desatualizadas.

O sistema de informações é uma ferramenta essencial para que as informações geradas sejam compartilhadas com a sociedade, através do Portal de Transparência. Ainda existem alguns problemas quanto à disponibilização de sinal de internet na região, e isso gera alguns problemas para os órgãos públicos, diminuindo a qualidade do serviço prestado via internet. Os SIs contábeis possibilitam que o gestor detenha um maior controle dos gastos públicos, trazendo mais qualidade desses gastos.

Essa pesquisa limitou-se pela quantidade de casos, que são três prefeituras municipais e uma câmara municipal. Outra limitação é a abordagem exploratória, que demanda validação do modelo gerado pela pesquisa empírica (Apêndice $A$ ).

Para pesquisas futuras, sugere-se que sejam feitos estudos de casos de outras prefeituras e órgãos municipais do estado de Rondônia, e também de outros estados brasileiros. Outra oportunidade de pesquisa é a utilização do texto do modelo (Figura 1), com instrumental estatístico e em número maior de prefeituras, a partir do modelo conceitual desta pesquisa (Apêndice A).

\section{REFERÊNCIAS}

Amorim, F. B., \& Tomaél, M. I. (2011). O Uso de Sistemas de Informação e seus Reflexos na Cultura Organizacional e no Compartilhamento de Informações. Perspectivas em Gestão \& Conhecimento, 1 (2236-417X).

Bardin, L. (2011). Análise de conteúdo (L. A. Reto \& A. Pinheiro, Trans.). São Paulo: Edições 70.

Biancolino, C. A., Maccari, E. A., Kniess, C. T., \& Costa, G. D. C. (2011). A Gestão de TI e o valor de uso dos ERP'S em sua perspectiva de pós implementação. Revista Eletrônica de Ciência Administrativa, 10, 5-19.

Ching, H. Y., Silveira, H. F. R. D., \& Freire, F. D. S. (2011). Gestão de custos na administração pública: estudo de casos do governo da Bahia e do Banco Central do Brasil. Revista de Economia e Administração, 10, 262-284.

Cpc, C. D. P. C.-. (2011). Pronunciamentos técnicos contábeis. Brasília: Conselho Federal de Contabilidade. 
Cpc 00 Estrutura conceitual para elaboração e apresentação das demonstrações contábeis (R1) (2011). Retrieved from http://www.cpc.org.br/index.php.

Cunha, M. a. V. C. D., \& Miranda, P. R. D. M. (2013). O Uso de TIC pelos Governos: uma proposta de agenda de pesquisa a partir da produção acadêmica e da prática nacional. O\&S, 20, 543-566. Recuperado de www.revistaoes.ufba.br

Delone, W. H., \& Mclean, E. R. (2003). The DeLone and McLean Model of Information Systems Success: A Ten-Year Update. Journal of Management Information Systems, 19(4), 9-30.

Ding, D. X., Hu, P. J.-H., \& Sheng, O. R. L. (2011). e-SELFQUAL: A scale for measuring online self-service quality. Journal of Business Research, 64, 508-515.

Engida, T. G., \& Bardill, J. (2013). Reforms of the public sector in the light of the new public management: A cases of Sub-Saharan Africa. Journal of Public Administration and Policy Research, 5, 1-7.

Fernandes, C. C. C., Jóia, L. A., \& Andrade, A. (2012). Resistência à implantação de sistemas de folha de pagamento na administração pública: um estudo multi-caso. Organizações \& Sociedade, 19, 145-164.

Gable, G. G., Sedera, D., \& Chan, T. (2008). Re-conceptualizing Information System Success: The IS-Impact Measurement Model. [Article]. Journal of the Association for Information Systems, 9(7), 1-32.

Geron, C. M. S., Finatelli, J. R., Faria, A. C. D., \& Romeiro, M. D. C. (2011). SPED - Sistema Público de Escrituração Digital: percepção dos contribuintes em relação os impactos de sua adoção. Revista de Educação e Pesquisa em Contabilidade, 5, 44-67.

Gil, A. C. (2010). Métodos e técnicas de pesquisa social (6 ed.). São Paulo: Atlas.

Gorla, N., Somers, T. M., \& Wong, B. (2010). Organizational impact of system quality, information quality, and service quality. The Journal of Strategic Information Systems, 19(3), 207-228.

Hartono, E., Li, X., Na, K.-S., \& Simpson, J. T. (2010). The role of the quality of shared information in interorganizational systems use. International Journal of Information Management, 30(5), 399-407.

Hsu, P.-F. (2013). Integrating ERP and e-business: Resource complementarity in business value creation. Decision Support Systems, $56,334-347$.

Lee, Y. W., Strong, D. M., Kahn, B. K., \& Wang, R. Y. (2002). AIMQ: a methodology for information quality assessment. Information \& Management, 40, 133-146. 
Machado, N., \& Holanda, V. B. D. (2010). Diretrizes e modelo conceitual de custos para o setor público a partir da experiência no governo federal do Brasil. Revista de Administração Pública, 44, 791-820.

Martinez, A. L., \& Alves Filho, E. M. (2012). Sistema de Gestão de Custos para uma Secretaria Municipal de Saúde. R. Cont. Ufba, 6, 52-65.

Matende, S., \& Ogao, P. (2013). Enterprise Resource Planning (ERP) System Implementation: A case for User participation. Procedia Technology, 9, 518-526.

Nascimento, A. M., \& Luft, M. C. M. S. (2012). Fatores promotores e inibidores ao uso de sistemas de informação em órgãos públicos. Revista Brasileira de Administração Científica, 3(2).

Nascimento, A. M. N., Luft, M. C. M. S., Araujo, G. F. D., \& Dacorso, A. L. R. (2011). Implantação de Sistemas de Informação em uma Secretaria Estadual. Revista Pensamento Contemporâneo em Administração, 5(1982-2596), 66-82.

Oliveira, D. D. L., Girardi, F., \& Gouveia Neto, S. C. D. (2011). Identificação de construtos relacionados ao impacto da TI no contexto de compartilhamento de informação: um estudo na prestação de serviços contábeis. Revista Eletrônica Sistemas \& Gestão, 6, 294-311.

Oliveira, D. D. L., \& Maçada, A. C. G. (2013). Capacidades de TI e desempenho da firma nas empresas brasileiras mais inovadoras no uso da TI. Revista de Administração e Inovação, 10, 79-97.

Oliveira, D. D. L., \& Oliveira, G. D. (2013). Valor das Capacidades de TI: Impactos sobre o Desempenho de Processos e de Firma nas Organizações Brasileiras. IV Encontro de Administração da Informação.

Oliveira, D. L., Lipke, F. A., \& Silva, S. R. F. (2013). Impacto das Capacidades de Internet Banking no Desempenho: Um estudo na perspectiva de clientes utilizando Partial Least Squares (PLS). International Conference on Information Resources Management.

Perez, G., Lex, S., Cesar, A. M. R. V. C., Silva, A. a. D., Medeiros Jr, A. D., \& Barbosa, C. a. P. (2012). Um Estudo Sobre os Efeitos da Adoção de Sistemas Integrados de Gestão (ERP) na Área Contábil. XXXVI EnANPAD.

Petter, S., Delone, W., \& Mclean, E. (2008). Measuring information systems success: models, dimensions, measures, and interrelationships. European Journal of Information Systems, 17, 236-263.

Petter, S., Delone, W., \& Mclean, E. R. (2012). The Past, Present, and Future of "IS Success". Journal of the Association for Information Systems, v. 13(5), p. 341-362.

Roses, L. K., Hoppen, N., \& Henrique, J. L. (2009). Management of perceptions of information technology service quality. Journal of Business Research, no 62(0148-2963.), 876-882. 
Sanchez, O. P., Cruz, M. A., \& Agapito, P. R. (2012). Investigação sobre o Sucesso de Sistemas para Ensino a Distância no Brasil: Uma Abordagem com Partial Least Square. XXXVI Encontro da ANPAD, Rio de Janeiro.

Seethamraju, R., \& Sundar, D. K. (2013). Influence of ERP systems on business process agility. IIMB Management Review, 25, 137-149.

Silva, B. a. M. D., \& Moraes, G. H. S. M. D. (2012). Influencia de los gestores del Uso de la TI en la gobernanza de TI. Revista Brasileira de Gestao de Negocios (Brazilian Journal of Business Management), 41.

Souza, A. a. D., \& Passolongo, C. (2005). Avaliação de Sistemas de Informações Contábeis: Estudo de Casos Múltiplos. EnANPAD.

Tallon, P. P. (2010). A Service Science Perspective on Strategic Choice, IT, and Performance in U.S. Banking. Journal of Management Information Systems, 26, 219-252.

Tallon, P. P., \& Kraemer, K. L. (2007). Fact or Fiction? A Sensemaking Perspective on the Reality Behind Executives' Perceptions of IT Business Value. Journal of Management Information Systems, 24, 13-54.

Yin, R. K. (2010). Estudo de caso: planejamento e métodos. Porto Alegre: Bookman.

Young, R., \& Poon, S. (2012). Top management support-almost always necessary and sometimessufficient for success: Findings from a fuzzy set analysis. International Journal of Project Management, 31, 943-957.

Zaied, A. N. H. (2012). An Integrated Success Model fo r Evaluating Information System in Public Sectors. Journal of Emerging Trends in Computing and Information Sciences, 3(6), 814-825.

Zheng, Y., Zhao, K., \& Stylianou, A. (2012). The impacts of information quality and systemquality on users' continuance intention in informationexchange virtual communities: An empirical investigation. Decision Support Systems, 56, 513-524.

\section{Apêndice A: Modelo Exploratório de sucesso de SI na Administração Pública: construtos e itens}

\begin{tabular}{|c|c|c|c|}
\hline Construtos & $\begin{array}{l}\text { Itens identificados na } \\
\text { literatura }\end{array}$ & Itens encontrados em campo & Fonte: \\
\hline \multirow{3}{*}{$\begin{array}{l}\text { Suporte da alta } \\
\text { gestão }\end{array}$} & $\begin{array}{l}\text { O suporte do gestor municipal } \\
\text { para o uso dos sistemas } \\
\text { contábeis e de custos é alto. }\end{array}$ & $\begin{array}{l}\text { O gestor se preocupa com o uso de SI com } \\
\text { o objetivo de cumprir normas. }\end{array}$ & $\begin{array}{l}\text { (Hartono et } \\
\text { al., 2010) }\end{array}$ \\
\hline & $\begin{array}{l}\text { O suporte da alta gestão (SAG) } \\
\text { é importante para o sucesso do } \\
\text { projeto. }\end{array}$ & $\begin{array}{l}\text { O gestor investe em TI com o objetivo de } \\
\text { cumprir normas. }\end{array}$ & $\begin{array}{l}\text { (Young \& } \\
\text { Poon, 2012) }\end{array}$ \\
\hline & $\begin{array}{l}\text { A liderança e apoio da alta } \\
\text { gestão favorecem o } \\
\text { compartilhamento de } \\
\text { informação entre órgãos, } \\
\text { melhorando a qualidade da } \\
\text { informação. }\end{array}$ & $\begin{array}{l}\text { Há compartilhamento de informações entre } \\
\text { os órgãos municipais, independe do apoio } \\
\text { da alta gestão. }\end{array}$ & $\begin{array}{l}\text { (D. D. L. } \\
\text { Oliveira et al. } \\
\text { 2011) }\end{array}$ \\
\hline
\end{tabular}


O dirigente político é comprometido com o projeto do sistema.

O sistema é de fácil uso, flexível, confiável, e de fácil aprendizagem.

A utilização inicial resulta em benefícios líquidos, que influenciam o uso subsequente

Qualidade do sistema do sistema.

O sistema de informação fornece informações úteis para a tomada de decisão.

Os sistemas auxiliam no planejamento de recursos organizacionais, atenuando os custos.

A informação é atualizada, confiável, compreensível e interpretável pelo usuário.

A informação contábil é relevante, fidedigna, além de ser comparável, verificável,

Qualidade da informação tempestiva e compreensível.

A relevância, oportunidade e precisão das informações são a chave para o sucesso de SI.

O sistema de informações é acessível, mas seguro.

O serviço prestado tem precisão, confiabilidade, competência técnica e empatia

Qualidade do serviço
Os custos com implantação de TI são altos, mas não é a prioridade dos órgãos públicos (Fernandes et estudados.

O sistema contábil é fácil de usar, é flexível, confiável, e de fácil aprendizagem. (Petter et al., Outro item é a experiência do usuário, que 2008) pode diminuir as dificuldades.

O SI proporciona agilidade nos procedimentos organizacionais e possibilita (Zheng et al. que o gestor tenha maior controle dos 2012) gastos.

As informações são importantes para a tomada de decisão, porém devem ser conferidas.

(Matende \& Ogao, 2013)

O uso do SI reduz custos com manutenção de impressora, impressão, e gastos com departamento pessoal. Os arquivos digitais estão sendo gradualmente utilizados.

(Seethamraju \& Sundar, 2013)

As informações colhidas nos SI contábeis são confiáveis, e conferidas diariamente.

(D. L. Oliveira et al., 2013)

O SI contábil possui informações relevantes, fidedignas, comparáveis, verificáveis, tempestivas e compreensível, pois necessitam dessas informações para

(Cpc, 2011) alimentar o Portal da Transparência.

As informações contidas em SI contábil são (Petter et al., precisas e oportunas.

Cada servidor público tem sua senha de acesso, para cada função, e depois as informações são consolidadas.

(Lee et al. 2002)

O serviço de TI é confiável, preciso e tem competência técnica.

(Petter et al., 2008)

O serviço prestado atende às necessidades dos servidores públicos, assim que solicitado, e precisam melhorar quanto ao tempo de resposta.
(Ding et al., 2011)
O serviço prestado atende às expectativas dos clientes (contribuintes).

\section{Continua}

\section{Continuação}

\begin{tabular}{|c|c|c|c|}
\hline Construtos & $\begin{array}{c}\text { Itens identificados na } \\
\text { literatura }\end{array}$ & Itens encontrados em campo & Fonte: \\
\hline \multirow[b]{2}{*}{$\begin{array}{l}\text { Qualidade do } \\
\text { serviço }\end{array}$} & $\begin{array}{l}\text { A prestação do serviço via } \\
\text { internet está mais rápida e } \\
\text { eficaz. }\end{array}$ & $\begin{array}{l}\text { A prestação de serviço de internet } \\
\text { encontra-se com problemas de } \\
\text { capacidade, e isso diminui a agilidade } \\
\text { para realizar atividades via internet. }\end{array}$ & $\begin{array}{l}\text { (A. M. N. } \\
\text { Nascimento et al., } \\
\text { 2011) }\end{array}$ \\
\hline & $\begin{array}{l}\text { Há capacidade de } \\
\text { estabelecer e gerenciar a } \\
\text { estratégia de fornecimento } \\
\text { de serviços. }\end{array}$ & $\begin{array}{l}\text { O serviço de TI é gerenciado de maneira } \\
\text { eficiente, porém, a rotatividade de } \\
\text { funcionário das empresas privadas pode } \\
\text { atrapalhar quanto a resolução de alguns } \\
\text { problemas. }\end{array}$ & $\begin{array}{l}\text { (Biancolino et al., } \\
\text { 2011) }\end{array}$ \\
\hline $\begin{array}{l}\text { Benefícios no } \\
\text { nível de } \\
\text { processos }\end{array}$ & $\begin{array}{l}\text { Os processos } \\
\text { organizacionais são } \\
\text { confiáveis e eficazes. }\end{array}$ & $\begin{array}{l}\text { Comparando-se o desempenho dos } \\
\text { últimos três anos, os processos } \\
\text { organizacionais são confiáveis e eficazes, } \\
\text { desde que sejam acompanhados } \\
\text { diariamente. }\end{array}$ & $\begin{array}{l}\text { ((D. D. L. Oliveira et } \\
\text { al., 2011); (Tallon, } \\
\text { 2010) }\end{array}$ \\
\hline
\end{tabular}

A prestação de encontra-se com problemas de capacidade, e isso diminui a agilid eficiente, porém, a rotatividade de funcionario das empresas privadas pode problemas. diariamente.
(A. M. N. Nascimento et al., 2011)

(Biancolino et al. 2011) 
Há redução de custos, melhorando o desempenho organizacional.

Os sistemas de informação não apenas monitoram os processos, são parte do processo devido à sua capacidade de transformar dados brutos em um produto.

A inovação contínua em SI/TI converte o uso de tecnologia em processos e aplicações inovadoras.

Há o aprimoramento do produto/serviço.

Melhoria nas relações com os contribuintes e tomada de decisões.

Há a otimização dos resultados dos programas governamentais. público.

Benefícios no
nível de
instituição
pública

Os aspectos de custos e investimentos em TI impactam o desempenho organizacional.

A informação de custos proporciona conteúdo fundamental para a tomada de decisões mais eficientes.

Os sistemas de informações
são avaliados pela sua relação custo/benefício.
Nos últimos três anos os custos com impressão, manutenção de impressora, e gastos com pessoal, entre outros custos, (Tallon, 2010) diminuíram, e isso melhorou o desempenho organizacional.

Os SI contábeis são indispensáveis para a realização dos processos.

(A. M. Nascimento \& Luft, 2012)

O SI proporcionou inovação nos processos organizacionais, mas sem sair (Perez et al., 2012) dos padrões das normas públicas.

Os serviços públicos são aprimorados (Tallon \& Kraemer, continuamente. 2007)

O uso de SI proporcionou facilidades para os contribuintes, além de colaborar com a redução de sonegação de impostos.

(Tallon \& Kraemer 2007)

Houve uma otimização dos resultados das unidades administrativas estudadas, nos últimos três anos.

(Ching et al., 2011);

(D. D. L. Oliveira \& Maçada, 2013)

Houve uma maior qualidade do gasto público, porém essa qualidade não depende apenas do SI, como também das (Ching et al., 2011) políticas públicas e das decisões do gestor público.

Os investimentos em TI impactaram positivamente 0 desempenho institucional, e o Portal da Transparência é um elo entre o setor público e a (Silva \& Moraes, sociedade.

2012)

As informações sobre os custos são importantes para a tomada de decisão, porém, em nenhuma das unidades administrativas estudadas possui SI de

(Machado custos, está em fase de implementação. através da licitação.

Fonte: Elaborado pelos autores. 